\title{
United States Geological Survey Fire Science-Fire Danger Monitoring and Forecasting
}

The convergence of large amounts of dry wildland fuels and weather favorable for fire ignition and spread signifies high potential for uncharacteristically large and dangerous fires. The ability to characterize the potential for hazardous fire activity requires measurements of fuel condition combined with information from weather forecasts. The availability of long fire histories adds a third dimension, fire probability, which can improve the ability to develop weekly forecasts of the location and number of large fires over a given region (Preisler and others, 2008).

The United States Geological Survey (USGS) uses moderate resolution satellite data to assess live fuel condition for estimating fire danger. Using 23 years of vegetation condition measurements, we are able to determine the relative greenness of current live fuels. High relative greenness values indicate the vegetation is healthy and vigorous; low greenness values indicate the vegetation is under stress, dry (possibly from drought),

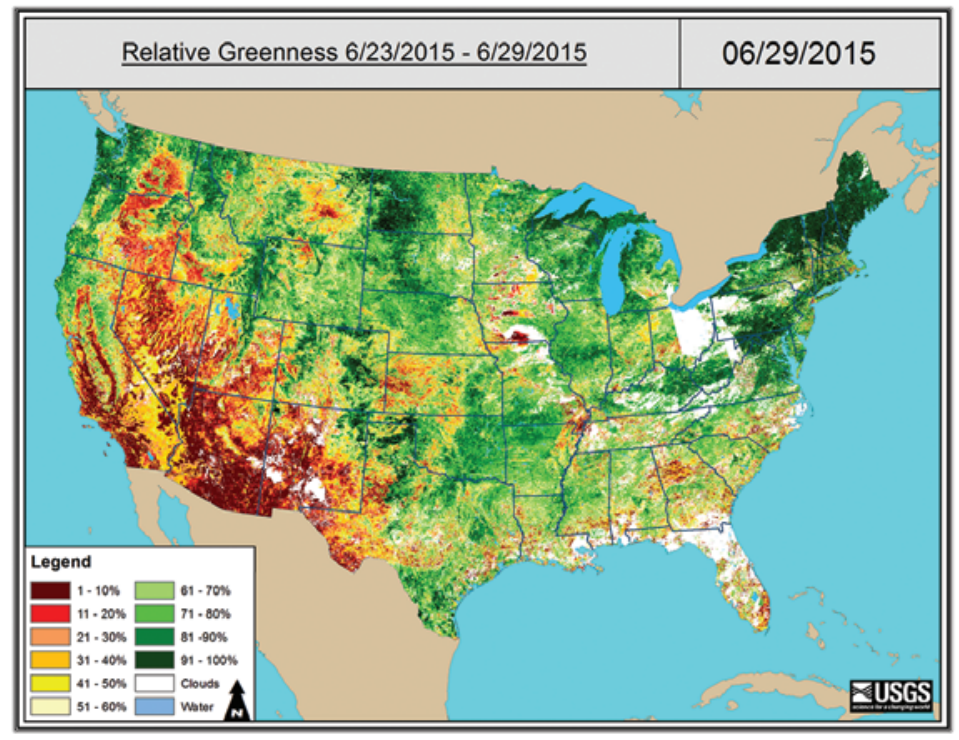

behind in annual development, or dead. Forest, shrub, and grassland vegetation with low relative greenness are susceptible to fire ignition during the fire season. The relative greenness for June 29, 2015, is shown in figure 1 .

The fire potential index (FPI) integrates weather information from the National Digital Forecast Database (http://www. nws.noaa.gov/ndfd/) and satellite-derived vegetation condition information, and is used to identify the areas most susceptible to fire ignition (Burgan et.al., 1998). The combination of relative greenness and weather information provides an estimate of the moisture condition of the live and dead vegetation. The FPI provides local and regional fire planners with a quantitative measure of fire ignition risk. The FPI for June 29, 2015, is shown in figure 2.

Each day, the USGS, in collaboration with the U.S. Forest Service, produces 7-day forecasts for the FPI, the expected number of large fires per Predictive Service Area, and the probability for a fire to exceed 100 acres in size. On a weekly basis, assessments of the relative greenness, the Normalized Difference Vegetation Index (NDVI), and the departure from the average weekly NDVI (fig. 3) are also produced. All can be viewed or downloaded for local analysis from the following Web site (http://firedanger.cr.usgs.gov).

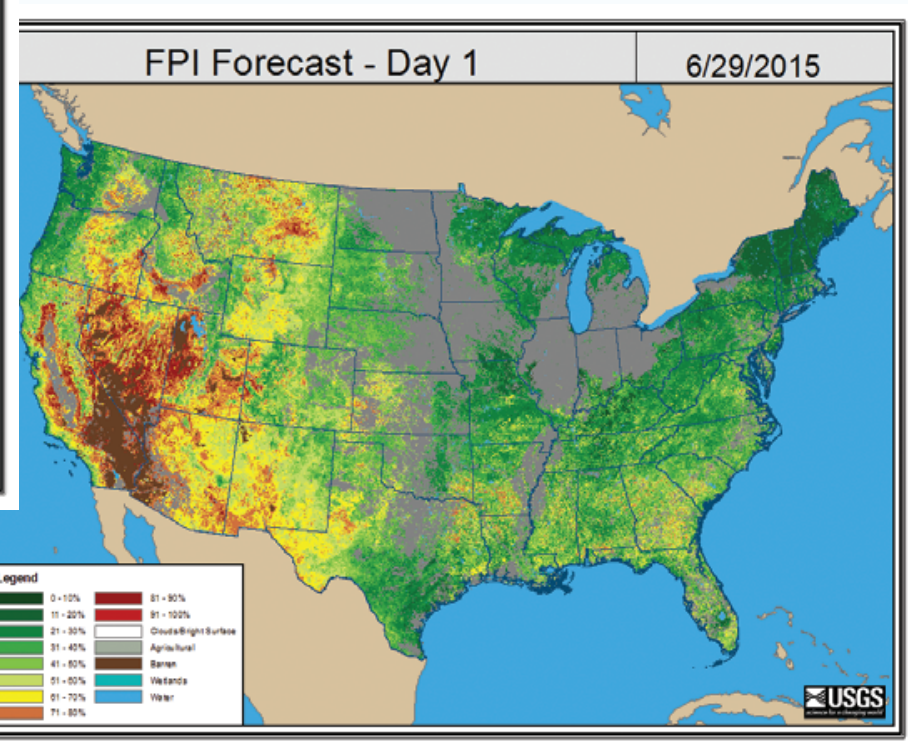

Figure 2. The fire potential index (FPI) image for June 29, 2015, shows the areas most $s$ usceptible to fire ignition. The FPI index is scaled from $1-100$, where 1 is the lowest potential and 100 is the highest potential. 


\section{References}

Preisler, H., Burgan, R., Eidenshink, J., and Klaver, J., 2008, Estimation and mapping of large wildfire probabilities based on satellite and gridded weather information: International Journal of Wildland Fire, v. 18, no. 5, p. 508-516.
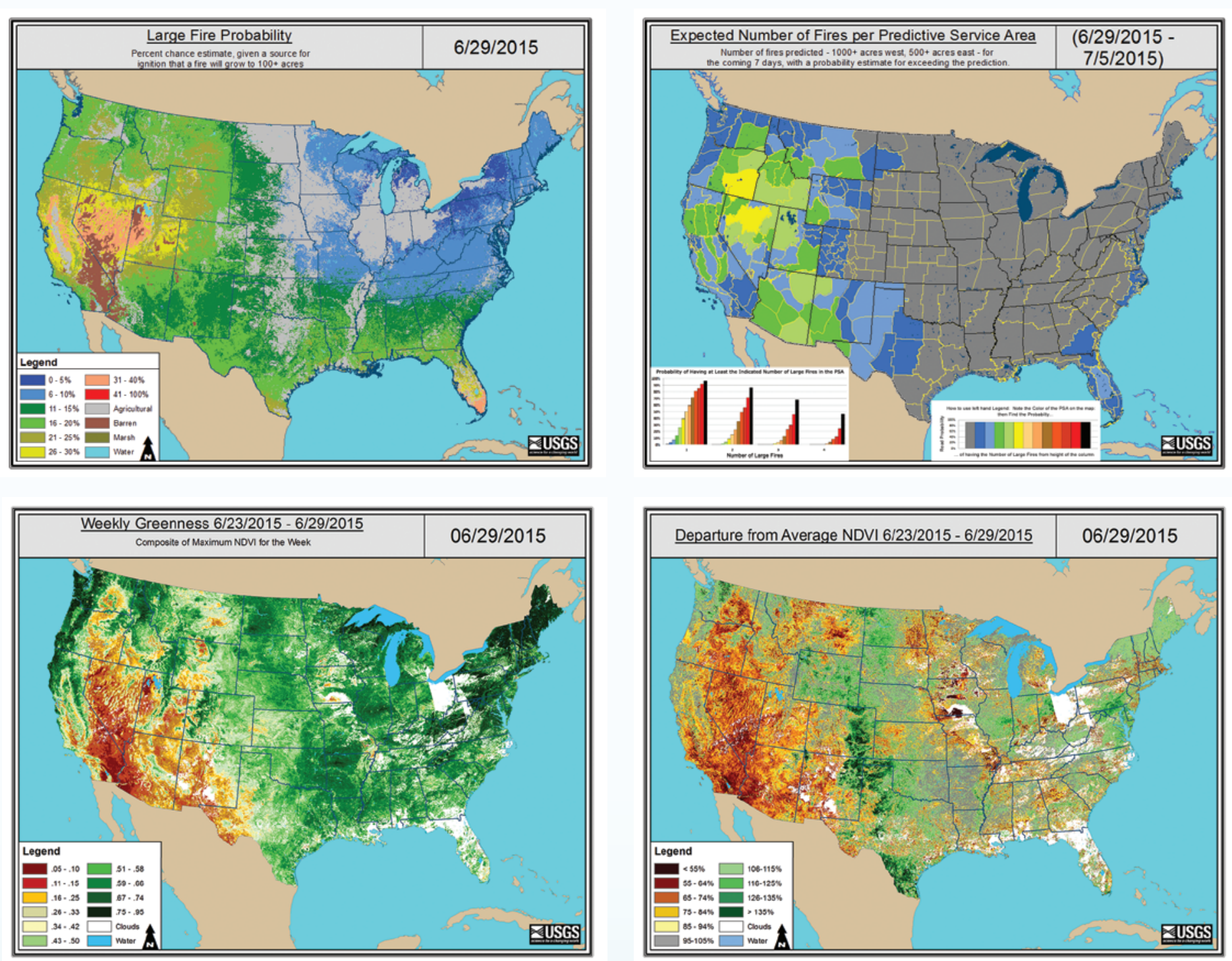

Burgan, R.E., Klaver, R.W., and Klaver, J.M., 1998, Fuel models and fire potential from satellite and surface observations: International Journal of Wildland Fire, v. 8, no. 3, p. $159-170$.

National Weather Service, 2007, National Digital Forecast Database (NDFD): National Weather Service database, accessed August 21, 2012, at http://www.nws.noaa.gov/ndfd/.

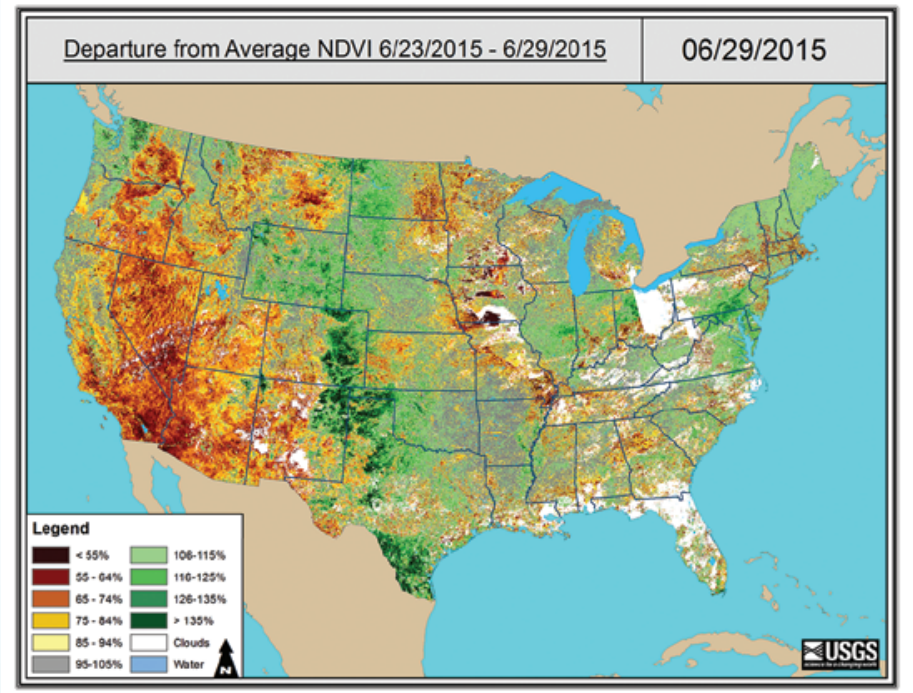

Figure 3. The 7-day forecast maps for the week of June 29, 2015. The large fire probability shows the percent chance that a fire at least 1 acre in size will grow to exceed 100 acres [based on present fire potential index (FPI) values]. Based on historical fire occurrence and current FPI values, the expected number of large fires per predictive service area map provides a probability estimate of exceeding a specified number of large fires. The weekly normalized difference vegetation (NDVI) index image shows the current greenness levels and the image showing departure from average indicates how much current NDVI levels differ from the historical average.

For more information

Fire Science Web site:

http://eros.usgs.gov/landscape-dynamics/fire-science

Fire Danger Monitoring and Forecasting Web site: http://firedanger.cr.usgs.gov/ 